\title{
Assessment of Genetic Diversity and Population Structure in Pea (Pisum sativum L.) Germplasm based on Morphological Traits and SSR Markers
}

\author{
Shalini Singh, B. Singh, V.R. Sharma ${ }^{1}$, M. Kumar, U. Sirohi ${ }^{2}$
}

10.18805/LR-4751

\begin{abstract}
Background: The study was undertaken to assess the genetic diversity and genetic structure among fifty-five pea accessions using morphological traits and SSR markers.

Methods: A total of 55 pea accessions were analyzed using eleven phenotypic traits and twenty SSR markers. The data obtained by morphological and molecular profiling was used for the analysis of genetic diversity and for the estimation of genetic diversity estimates, correlation, principal components analysis and population structure.

Result: This study reveals that majority of genetic variation was due to variation within population and were clustered into two distinct groups, which reveals a high admixture within individuals. Accessions viz., VRP-82, VRP-320, VRP-194, VRP-375, EC-97280 and EC8724 , showed great diversity as compared to the other accessions based on both morphological and molecular markers. These accessions may assist in developing and planning breeding strategies aimed to produce new varieties in the future.
\end{abstract}

Key words: Genetic diversity, Pea, Population structure, SSR markers.

\section{INTRODUCTION}

Garden pea (Pisum sativum $\mathrm{L} ., 2 \mathrm{n}=14$ ) is a widely cultivated vegetable crop native to Syria, Turkey, Israel and Ethiopia, for its versatile uses as pulses and livestock feed (Choudhury et al., 2007). In India, it is mostly grown in Uttar Pradesh, Madhya Pradesh, Bihar, Assam and Odisha with an area of 0.54 million hectares and an annual production of 5.4 million tonnes (NHB, 2019). It is grown for its tender green pods, dried seeds, canned, frozen or dehydrated form (Santalla et al., 2001).

Widespread cultivation of the crop, replacing landraces and traditional population, particularly the one resistant to biotic and abiotic stress, narrowed down the genetic base and has led to the loss of genetic variability. New breeding challenges imposed by global climate change and to meet the global demand, pea breeders have to undertake more efficient methods of selection and better take advantage of the large genetic diversity present in the gene pool using advanced methods. Phenotypic traits are widely used as the only accepted valid marker type for defining germplasm groups by the international union for the protection of new varieties of plants (UPOV) (Smykal et al., 2008). Morphological characteristics represent the action of many genes but they can be unreliable due to the significant environmental influences. In contrast, molecular markers are useful to complement the morphological traits because they are independent of environmental effects and allow identification of the cultivar in the early stages of crop.

Among the various DNA markers available for molecular profiling of genotypes SSRs or microsatellites are highly reliable, accurate, co-dominant, generally highly polymorphic and also cost-effective (Jain et al., 2014). In
Department of Horticulture, Sardar Vallabhbhai Patel University of Agriculture and Technology, Meerut-250 110, Uttar Pradesh, India. ${ }^{1}$ CSIR-National Botanical Research Institute, Lucknow-226 001, Uttar Pradesh, India.

${ }^{2}$ Department of Agriculture Biotechnology, Sardar Vallabhbhai Patel University of Agriculture and Technology, Meerut-250 110, Uttar Pradesh, India.

Corresponding Author: Shalini Singh, Department of Horticulture, Dr. Khem Singh Gill Akal College of Agriculture, Eternal University, Baru Sahib-173 001, Himachal Pradesh, India.

Email: drshalinisinghhorti@gmail.com

How to cite this article: Singh, S., Singh, B., Sharma, V.R., Kumar, M., Sirohi, U. (2021). Assessment of Genetic Diversity and Population Structure in Pea (Pisum sativum L.) Germplasm based on Morphological Traits and SSR Markers. Legume Research. DOI: $10.18805 /$ LR-4751.

Submitted: 26-07-2021 Accepted: 19-10-2021 Online: 03-11-2021

pea, various genetic diversity studies were done using phenotypic traits (Uzma et al., 2018). Loridon et al. (2005) initially developed a set of SSRs for genetic diversity and linkage mapping of pea. Later, Rana et al. (2017) and Tahir et al. (2018) reported use of some polymorphic SSR markers for genetic diversity studies in pea. However, most of the studies involved accessions from the iso-climatic regions of the world.

In addition, a comprehensive study to evaluate the genetic diversity of the pea germplasms in sub-tropical conditions like Western Uttar Pradesh conditions has not been carried out in India and there is need to increase the production and productivity to meet rising population. Hence, 
Assessment of Genetic Diversity and Population Structure in Pea (Pisum sativum L.) Germplasm based on Morphological Traits...

the objective of the present study was to assess the level of genetic diversity within fifty-five collected pea accessions using morphological traits and SSR loci in Western Uttar Pradesh conditions.

\section{MATERIALS AND METHODS}

A total of fifty-five pea accessions were grown in randomized block design with three replications at Horticultural Research Center, SVPUAT, Meerut (U.P.), India (Table 1). Standard agronomic practices were followed to raise the crop. The traits viz., DF-days to $50 \%$ flowering, $\mathrm{PH}$ - plant height $(\mathrm{cm})$, NFFN-number of first fruiting node, LFFN-length of first fruiting node $(\mathrm{cm})$, NPP-number of pods per plant, LP-length of pod (cm), WP-width of pod (cm), NSP-number of seeds per pod, GPY-green pod yield per plant (g), SW-shell weight per plant $(\mathrm{g})$ and SY-seed yield per plant $(\mathrm{g})$ were recorded for the five randomly selected plants in each replication. The mean values for each trait were analysed for descriptive statistics and genetic diversity analysis.

For genotyping, genomic DNA was isolated using CTAB extraction method (Doyle and Doyle, 1987) and was quantified using Bio-Rad's SpecTM Plus spectrophotometer. PCR amplification was performed using 20 SSR primer pairs (Table 2) and evaluated according to Kumar et al. (2019). A dendrogram was constructed based on the Jaccard's similarity matrix using the UPGMA clustering by using the software NTSYS-pc (Rohlf, 1998).

PIC-Polymorphism information content (Bostein et al., 1980); Marker Index (MI) (Nagaraju et al., 2001) and RpResolving Power (Prevost and Wilkinson, 1999) was estimated. Furthermore, various other genetic diversity estimates (Huang et al., 2021) were calculated using POPGENE v.1.32 (Yeh and Boyle, 1997). Principal Component Analysis (PCA) was done using $\mathrm{R}$ software (Venables and Ripley, 2002). Bayesian model-based clustering was also performed in STRUCTURE software, v.2.3.3. (Pritchard et al., 2000) to identify the population structure of the germplasm using ancestry model with admixture and correlated allele frequency model was set according to Kumar et al. (2019). Analysis of molecular variance (AMOVA) (Excoffier et al., 1992; Excoffier et al., 1993) was performed to calculate variance components within and among the population with the help of GenALEx 6.5 (Peakall and Smouse, 2006). The mantel's test was done to correlate the morphological and molecular genetic matrices using XLStat Software (Smykal et al., 2008).

\section{RESULTS AND DISCUSSION}

Based on phenotypic data, analysis of variance revealed that, all the character studied showed significant variation (Table 3). On the basis of Mahalanobis $D^{2}$ values, all the pea accessions were best grouped into 6 clusters (Rahman et al., 2013). Comparative assessment of cluster means showed that for improving specific characters, the accessions should be selected from the cluster having high mean value for that particular character. This comparison
Table 1: List of pea accessions used and their source of collection.

\begin{tabular}{|c|c|}
\hline Genotypes & Source \\
\hline VRP-3 & I.I.V.R., Varanasi \\
\hline VRP-13 & I.I.V.R., Varanasi \\
\hline VRP-26 & I.I.V.R., Varanasi \\
\hline VRP-194 & I.I.V.R., Varanasi \\
\hline VRP-222 & I.I.V.R., Varanasi \\
\hline VRP-375 & I.I.V.R., Varanasi \\
\hline VRP-324 & I.I.V.R., Varanasi \\
\hline VRP-115 & I.I.V.R., Varanasi \\
\hline VRP-69 & I.I.V.R., Varanasi \\
\hline VRP-313 & I.I.V.R., Varanasi \\
\hline VRP-311 & I.I.V.R., Varanasi \\
\hline VRP-73 & I.I.V.R., Varanasi \\
\hline VRP-228 & I.I.V.R., Varanasi \\
\hline VRP-321 & I.I.V.R., Varanasi \\
\hline VRP-320 & I.I.V.R., Varanasi \\
\hline VRP-355 & I.I.V.R., Varanasi \\
\hline VRP-16 & I.I.V.R., Varanasi \\
\hline VRP-22 & I.I.V.R., Varanasi \\
\hline VRP-122 & I.I.V.R., Varanasi \\
\hline VRP-383 & I.I.V.R., Varanasi \\
\hline VRP-284 & I.I.V.R., Varanasi \\
\hline VRP-65 & I.I.V.R., Varanasi \\
\hline VRP-223 & I.I.V.R., Varanasi \\
\hline VRP-402 & I.I.V.R., Varanasi \\
\hline VRP-382 & I.I.V.R., Varanasi \\
\hline VRP-176 & I.I.V.R., Varanasi \\
\hline VRP-273 & I.I.V.R., Varanasi \\
\hline VRP-327 & I.I.V.R., Varanasi \\
\hline VRP-107 & I.I.V.R., Varanasi \\
\hline VRP-156 & I.I.V.R., Varanasi \\
\hline VRP-174 & I.I.V.R., Varanasi \\
\hline VRP-95 & I.I.V.R., Varanasi \\
\hline VRP-49 & I.I.V.R., Varanasi \\
\hline VRP-276 & I.I.V.R., Varanasi \\
\hline VRP-82 & I.I.V.R., Varanasi \\
\hline VRP-145 & I.I.V.R., Varanasi \\
\hline VRP-343 & I.I.V.R., Varanasi \\
\hline VRP-131 & I.I.V.R., Varanasi \\
\hline VRP-248 & I.I.V.R., Varanasi \\
\hline VRP-64 & I.I.V.R., Varanasi \\
\hline VRPM-15 & I.I.V.R., Varanasi \\
\hline VP-233 & I.I.V.R., Varanasi \\
\hline EC-97280 & N.B.P.G.R., New Delhi \\
\hline EC-8372 & N.B.P.G.R., New Delhi \\
\hline EC-8724 & N.B.P.G.R., New Delhi \\
\hline EC-71944 & N.B.P.G.R., New Delhi \\
\hline MO-23 & I.I.V.R., Varanasi \\
\hline MO-19 & I.I.V.R., Varanasi \\
\hline KS-228 & I.I.V.R., Varanasi \\
\hline DPP-94/8-06 & I.I.V.R., Varanasi \\
\hline Kashi Uday & I.I.V.R., Varanasi \\
\hline Kashi Mukti & I.I.V.R., Varanasi \\
\hline Kashi Shakti & I.I.V.R., Varanasi \\
\hline Kashi Samridhi & I.I.V.R., Varanasi \\
\hline Kashi Nandini & I.I.V.R., Varanasi \\
\hline
\end{tabular}


Assessment of Genetic Diversity and Population Structure in Pea (Pisum sativum L.) Germplasm based on Morphological Traits...

Table 2: List of SSR primers with their sequence and annealing temperature.

\begin{tabular}{|c|c|c|}
\hline Primer & Sequences & $\begin{array}{l}\text { Annealing } \\
\text { temp }\left({ }^{\circ} \mathrm{C}\right)\end{array}$ \\
\hline \multirow[t]{2}{*}{ PEA-01 } & F: 5'GAACTAGAGCTGATAGCATGT3' & 67 \\
\hline & R: 5'GCATGCAAAAGAACGAAACAGG3' & \\
\hline \multirow[t]{2}{*}{ PEA-02 } & F: 5'GACATTGCCAATAACTGG3' & 65 \\
\hline & R: 5'GGTTCTGTTCTCAATACAAG3' & \\
\hline \multirow[t]{2}{*}{ PEA-03 } & F: 5'GATGTGATAGGCCTAGAACAAGC3' & 69 \\
\hline & R: 5'CAGTCACACACTACAAGAGATC3' & \\
\hline \multirow[t]{2}{*}{ PEA-04 } & F: 5'GTGGCTGATCCTGTCAACAA3' & 66 \\
\hline & R: 5'CAACAACCAAGAGCAAAGAAAA3' & \\
\hline \multirow[t]{2}{*}{ PEA-05 } & F: 5'CCCAGTGAAGAAGGTCAACA3' & 62 \\
\hline & R: 5'CAATGGTGGCAAATAGGAAA3' & \\
\hline \multirow{2}{*}{ PEA-07 } & F: 5'CCATTTCTGGTTATGAAACCG3' & 65 \\
\hline & R: 5'CTGTTCCTCATTTTCAGTGGG3' & \\
\hline \multirow[t]{2}{*}{ PEA-09 } & F: 5'CTGGAATTCTTGCGGTTTAAC3' & 67 \\
\hline & R: 5'CGTTTTGGTTACGATCGAGCAT3' & \\
\hline \multirow[t]{2}{*}{ PEA-11 } & F: 5'CACACGATAAGAGCATCTGC3' & 58 \\
\hline & R: 5'GCTTGAGTTGCTTGCCAGCC3' & \\
\hline \multirow[t]{2}{*}{ PEA-12 } & F: 5'TGGATTGGATTGGATGATGA3' & 63 \\
\hline & R: 5'TGGAGCCCTTAGTCCACAAC3' & \\
\hline \multirow[t]{2}{*}{ PEA-14 } & F: 5'CCAAGAAAGGCTTATCAACAGG3' & 68 \\
\hline & R: 5'TGCTTGTGTCAAGTGATCAGTG3' & \\
\hline \multirow[t]{2}{*}{ PEA-15 } & F: 5'AATTTGAAAGAGGCGGATGTG3' & 67 \\
\hline & R: 5'АСТTСТСТССААСАТССААСGАЗ' & \\
\hline \multirow[t]{2}{*}{ PEA-18 } & F: 5'TGTAGAAGCATAAGAGCGGGTG3' & 68 \\
\hline & R: 5'TGCAACGCT CTT GTT GAT GATT3' & \\
\hline \multirow[t]{2}{*}{ PEA-19 } & F: 5'TAGTTTTGAACTTTGGCCGTAT3' & 69 \\
\hline & R: 5'CACACCCTAATCTAGGCTATCC3' & \\
\hline \multirow[t]{2}{*}{ PEA-20 } & F: 5'CAATCGATCAGACAGTCCСCTA3' & 66 \\
\hline & R: 5'AAGCTCACCTGGTTATGTCCCT3' & \\
\hline \multirow[t]{2}{*}{ PEA-21 } & F: 5'TGTGGGGCTTGTTACACTGA3' & 65 \\
\hline & R: 5'AGCTACCATAACAGACAAAACC3' & \\
\hline \multirow[t]{2}{*}{ PEA-23 } & F: 5'TTCCAACCATGGAAGCTTTT3' & 62 \\
\hline & R: 5'TTCTTCGTCGGGTACAGTGA3' & \\
\hline \multirow[t]{2}{*}{ PEA-26 } & F: 5'AGCTCTTTCTTCCACCACСАЗ' & 58 \\
\hline & R: 5'AGCTCTTTCTTCCACCACCA3' & \\
\hline \multirow[t]{2}{*}{ PEA-27 } & F: 5'TTTAGCACAGAACAGCGTAGT3' & 64 \\
\hline & R: 5'TAACGCCCTTGAGAATTTCG3' & \\
\hline \multirow[t]{2}{*}{ PEA-28 } & F: 5'AAATGGCCGTTTTATGATCG3' & 61 \\
\hline & R: 5'CGGAGCTGAACCTTCTGGTA3' & \\
\hline \multirow[t]{2}{*}{ PEA-29 } & F: 5'GCTACTGGAGGAGGCTTTCA3' & 58 \\
\hline & R: 5'GCCTTCTACACAACGGCTTC3' & \\
\hline
\end{tabular}

indicates that clusters I and IV had better cluster means for most of the characters, therefore, these clusters might be considered better for selecting accessions as divergent parents (Table 4). The similar results are exhibited with the findings Shrivastava et al., (2012).

The twenty primers which generated clear and distinct polymorphic alleles used in this study produced a total of 40 alleles. The effective number of alleles produced per locus ranged from 1 to 2 with an average of 1.5 bands per locus (Fig 1). Similar reports were presented by Handerson et al., (2014) and Rana et al., (2017). Further, the most informative locus under this study was PEA-03 with PIC value of (0.996). A marker with PIC value greater than 0.5 is considered to be a very informative (Prakash et al., 2016). Few studies also suggested that a greater number of accessions and primer pairs need for improving allelic richness (Negisho et al., 2017). The highest (0.50) and lowest (0.03) expected heterozygosity $(\mathrm{He})$ values obtained were with PEA-14 and PEA-11, 26, 27 respectively. Whereas, highest observed heterozygosity and Shannon's information index was obtained with PEA-14. It formed the average Shannon information index (I) value of 0.44 , which was lower as compared to studies of Rana et al., (2017). Observed heterozygosity $\left(\mathrm{H}_{\mathrm{o}}\right)$ was ranged from 0.0 to 0.92 in primers PEA-3 and PEA-14, respectively. Expected heterozygosity $\left(\mathrm{H}_{\mathrm{e}}\right)$ was ranged from 0.03 to 0.5 in primers PEA-29 and PEA-1 (Table 5).

Lower estimates obtained for all the diversity parameters indicate low allelic richness in the analysed germplasm, which implies more number of germplasm were need to be included for improving allelic richness. Furthermore, $R p$ varied between 0.51 to 3.20 and the value of $\mathrm{Ml}$ ranged between 0.08 to 2.97 , which shows informative and polymorphic content of primers for assessment of diversity.

Jaccard's similarity index was ranged from 0.589 between accessions 'EC-97280 and VRP-320' (distant) to 0.974 between accessions 'VRP-49 and VRP- 95' (closest). Cluster analysis based UPGMA dendrogram (Fig 2) outlined by SSR primer pairs grouped the 55 pea accessions into four clusters. PCA showed similarities in grouping with UPGMA and showed the $76 \%$ of variability based on first 4 components. PC1 showed $64 \%$ of total variability with Eigen value of 35.43 . Whereas, the components namely, PC2, PC3 and $\mathrm{PC} 4$ revealed $4.5 \%, 4.3 \%$ and $3.38 \%$ of variability, respectively (Fig 3 ). The results agreed with other studies which indicate that these characteristics contribute

Table 3: Descriptive statistics of morphological data.

\begin{tabular}{|c|c|c|c|c|c|c|c|c|c|c|c|}
\hline Statistics & DF $(50 \%)$ & $\mathrm{PH}$ & NFFN & LFFN & NPP & LP & WP & NSP & GPY & SW & SY \\
\hline Minimum & 59.67 & 29.67 & 4.42 & 12.52 & 3.42 & 5.11 & 1.01 & 3.75 & 10.81 & 3.15 & 5.29 \\
\hline Maximum & 67.67 & 177.81 & 12.50 & 42.85 & 22.84 & 9.07 & 1.88 & 7.33 & 62.52 & 33.24 & 30.59 \\
\hline Median & 63.00 & 69.16 & 9.08 & 30.43 & 8.33 & 7.33 & 1.32 & 5.58 & 23.85 & 12.76 & 11.39 \\
\hline Mean & 63.18 & 74.40 & 8.85 & 29.31 & 9.57 & 7.25 & 1.31 & 5.44 & 27.46 & 14.18 & 13.37 \\
\hline Variance $(n-1)$ & 5.51 & 560.19 & 4.04 & 45.00 & 23.03 & 0.91 & 0.03 & 0.72 & 169.51 & 48.52 & 47.53 \\
\hline Standard deviation $(n-1)$ & 2.35 & 23.67 & 2.01 & 6.71 & 4.80 & 0.95 & 0.17 & 0.85 & 13.02 & 6.97 & 6.89 \\
\hline
\end{tabular}


Assessment of Genetic Diversity and Population Structure in Pea (Pisum sativum L.) Germplasm based on Morphological Traits...

Table 4: Cluster wise mean values of 11 morphological traits in pea (Pisum sativum L.).

\begin{tabular}{lccccccccccc}
\hline Clusters & DF (50\%) & PH & NFFN & LFFN & NPP & LP & WP & NSP & GPY & SW & SY \\
\hline I & 62.43 & $60.97^{*}$ & $7.10^{*}$ & $22.47^{*}$ & $15.52^{* *}$ & 7.60 & 1.33 & 5.33 & $47.52^{* *}$ & $23.54^{* *}$ & $24.57^{* *}$ \\
II & 63.70 & 64.89 & 8.00 & 25.63 & 7.84 & 6.52 & $1.15^{*}$ & $4.87^{*}$ & 19.01 & 9.92 & 9.25 \\
III & 62.19 & 69.45 & 8.66 & 28.14 & $5.78^{*}$ & 7.50 & $1.47^{* *}$ & 5.47 & $17.60^{*}$ & 8.90 & 8.50 \\
IV & $66.25^{* *}$ & $139.61^{* *}$ & 8.27 & $35.01^{* *}$ & 6.05 & $6.48^{*}$ & 1.22 & $6.27^{* *}$ & 15.29 & $8.39^{*}$ & $6.93^{*}$ \\
V & $62.07^{*}$ & 73.40 & 10.35 & 34.54 & 9.73 & $8.06^{* *}$ & 1.34 & 5.97 & 34.42 & 17.82 & 16.82 \\
VI & 65.08 & 79.18 & $10.72^{* *}$ & 34.67 & 12.26 & 6.61 & 1.19 & 5.06 & 26.56 & 14.84 & 11.47 \\
\hline
\end{tabular}

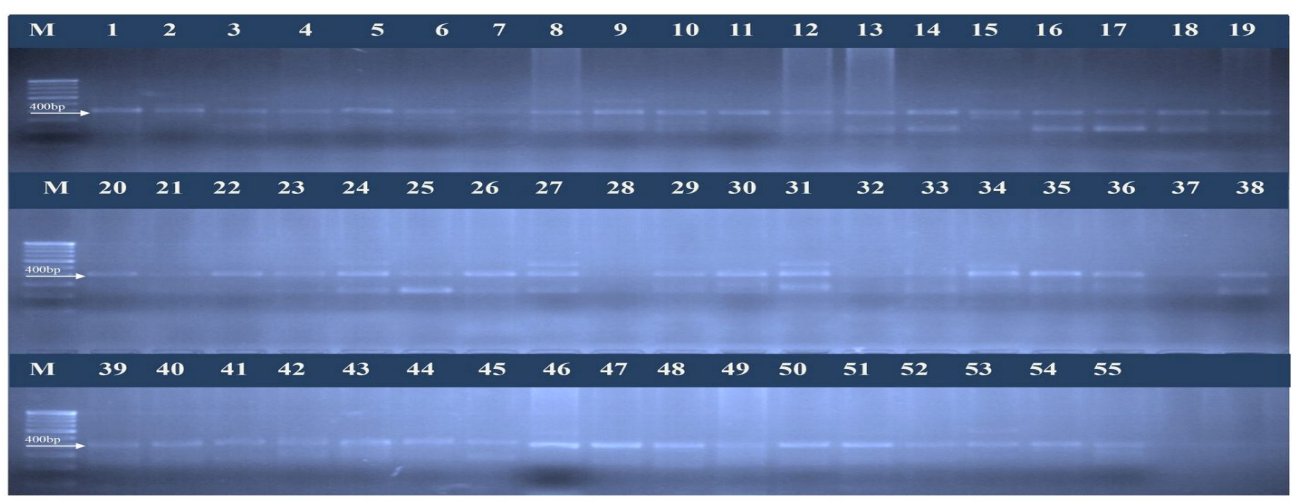

Fig 1: SSR profiling pattern of 55 accessions of pea with PEA-05 primer (M-100bp molecular marker).

Table 5: Primer name, Molecular weight range, PIC, RP, MI, polymorphic and monomorphic bands, polymorphism \% and genetic diversity estimates of SSR primers.

\begin{tabular}{|c|c|c|c|c|c|c|c|c|c|c|c|c|}
\hline $\begin{array}{l}\text { Primer } \\
\text { name }\end{array}$ & $\begin{array}{c}\text { Molecular weight } \\
\text { range }(b p)\end{array}$ & PIC & $\mathrm{RP}$ & MI & na & ne & I & Obs_Hom & Obs_Het & Exp_Hom & Exp_Het & $\mathrm{Nei}$ \\
\hline PEA-01 & $200-500$ & 0.990 & 2.10 & 2.97 & 2.000 & 1.994 & 0.692 & 0.746 & 0.255 & 0.497 & 0.503 & 0.499 \\
\hline PEA-02 & $100-300$ & 0.980 & 1.66 & 1.96 & 2.000 & 1.948 & 0.680 & 0.236 & 0.764 & 0.509 & 0.491 & 0.487 \\
\hline PEA-03 & 360 & 0.996 & 0.51 & 0.99 & 2.000 & 1.612 & 0.567 & 1.000 & 0.000 & 0.617 & 0.383 & 0.380 \\
\hline PEA-04 & 800 & 0.376 & 1.78 & 0.38 & 2.000 & 1.241 & 0.345 & 1.000 & 0.000 & 0.804 & 0.196 & 0.194 \\
\hline PEA-05 & $200-400$ & 0.977 & 2.28 & 2.93 & 2.000 & 1.984 & 0.689 & 0.382 & 0.618 & 0.500 & 0.500 & 0.496 \\
\hline PEA-07 & 120 & 0.770 & 1.38 & 0.77 & 2.000 & 1.746 & 0.618 & 1.000 & 0.000 & 0.569 & 0.431 & 0.427 \\
\hline PEA-09 & 60 & 0.590 & 1.60 & 0.59 & 2.000 & 1.471 & 0.500 & 1.000 & 0.000 & 0.677 & 0.323 & 0.320 \\
\hline PEA-11 & 210 & 0.080 & 1.96 & 0.08 & 2.000 & 1.037 & 0.091 & 1.000 & 0.000 & 0.964 & 0.036 & 0.036 \\
\hline PEA-12 & 230 & 0.190 & 1.90 & 0.19 & 2.000 & 1.075 & 0.156 & 1.000 & 0.000 & 0.929 & 0.071 & 0.070 \\
\hline PEA-14 & $200-400$ & 0.894 & 2.00 & 1.78 & 2.000 & 2.000 & 0.693 & 0.073 & 0.927 & 0.495 & 0.505 & 0.500 \\
\hline PEA-15 & $50-400$ & 0.769 & 3.20 & 1.54 & 2.000 & 1.471 & 0.500 & 0.600 & 0.400 & 0.677 & 0.323 & 0.320 \\
\hline PEA-18 & 480 & 0.985 & 0.70 & 0.99 & 2.000 & 1.826 & 0.645 & 1.000 & 0.000 & 0.544 & 0.456 & 0.452 \\
\hline PEA-19 & 220 & 0.686 & 1.49 & 0.69 & 2.000 & 1.612 & 0.567 & 1.000 & 0.000 & 0.617 & 0.383 & 0.380 \\
\hline PEA-20 & $200-300$ & 0.968 & 1.85 & 1.94 & 2.000 & 1.990 & 0.691 & 0.146 & 0.855 & 0.498 & 0.502 & 0.497 \\
\hline PEA-21 & $100-300$ & 0.875 & 2.56 & 1.75 & 2.000 & 1.862 & 0.656 & 0.382 & 0.618 & 0.533 & 0.467 & 0.463 \\
\hline PEA-23 & 290 & 0.343 & 1.80 & 0.34 & 2.000 & 1.198 & 0.305 & 1.000 & 0.000 & 0.833 & 0.167 & 0.165 \\
\hline PEA-26 & 250 & 0.078 & 1.96 & 0.08 & 2.000 & 1.037 & 0.091 & 1.000 & 0.000 & 0.964 & 0.036 & 0.036 \\
\hline PEA-27 & 270 & 0.078 & 1.96 & 0.08 & 2.000 & 1.037 & 0.091 & 1.000 & 0.000 & 0.964 & 0.036 & 0.036 \\
\hline PEA-28 & 240 & 0.135 & 1.93 & 0.14 & 2.000 & 1.075 & 0.156 & 1.000 & 0.000 & 0.929 & 0.071 & 0.070 \\
\hline PEA-29 & 260 & 0.078 & 1.96 & 0.08 & 2.000 & 1.037 & 0.091 & 1.000 & 0.000 & 0.964 & 0.036 & 0.036 \\
\hline Average & & 0.59 & & & 2.000 & 1.513 & 0.441 & 0.778 & 0.222 & 0.704 & 0.296 & 0.293 \\
\hline
\end{tabular}

na= Observed number of alleles; ne = Effective number of alleles; I: Shannon's Information index; Observed (Obs) and Expected (Exp) homozygosity (Hom) and heterozygosity (het); Nei: Nei's (1973) expected heterozygosity. 
maximally to a genetic divergence of pea (Cupic et al., 2009; Suman et al., 2019; Singh et al., 2021).

Based on population structure analysis, the $\Delta \mathrm{K}$ value observed maximum at $\Delta k=2$ which implies all accessions grouped into two groups that shows highly admixture population (Fig 4). This also showed that there is no correspondence of genotypic matrix with the geographical location. Similar type of finding where reported by Jain et al., (2014); Rana et al., (2017) and Tahir et al., (2018). Whereas, in case of AMOVA analysis, it was observed that the genetic diversity of present population is mainly due to within population almost about $73 \%$ and the variation due among population is only $24 \%$. The variance among the population is low. But all the total comparison, however, showed significant variation between accessions because of the presence of a large number and differences in the frequency of unique and rare alleles between accessions. Similar results were obtained by Rana et al., (2017). Based on the Mantel's test between the morphological and molecular matric indicated the low to medium positive significant correlation. Similar type of low to medium correlation between the matrices was obtained by Smykal et al., (2008)

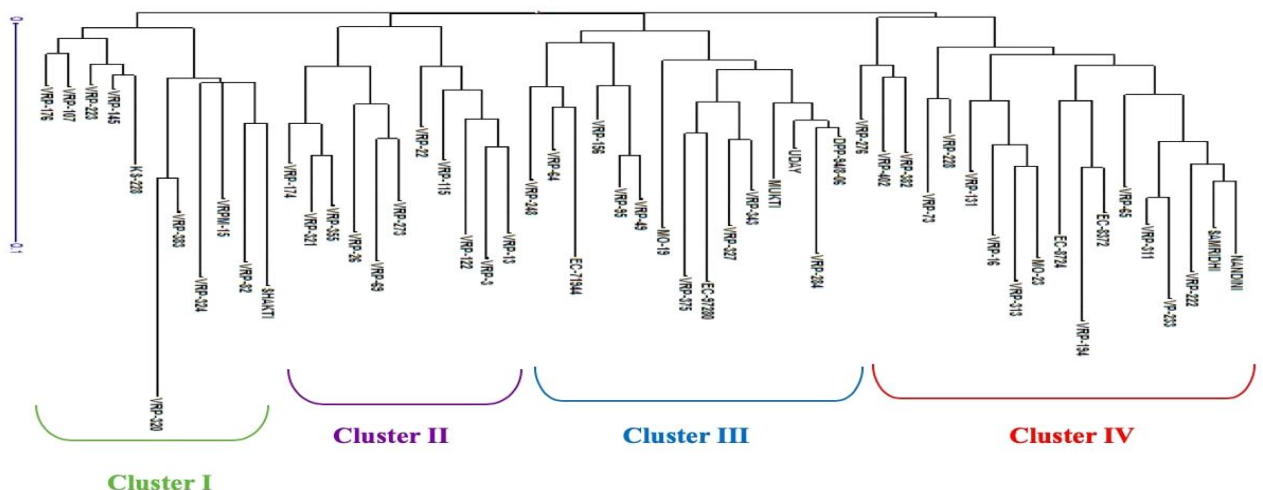

Fig 2: Dendrogram represents clustering of 55 pea accessions constructed using UPGMA based on Jaccard's similarity coefficient obtained from SSR analysis.

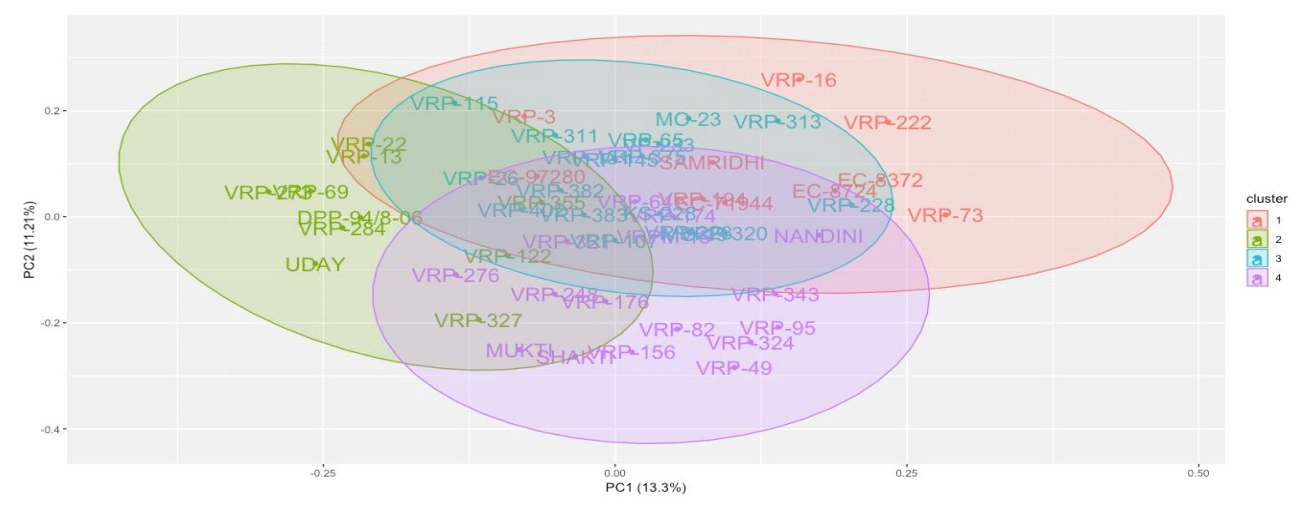

Fig 3: 2-Dimensional principal component analysis based on SSR markers in pea.
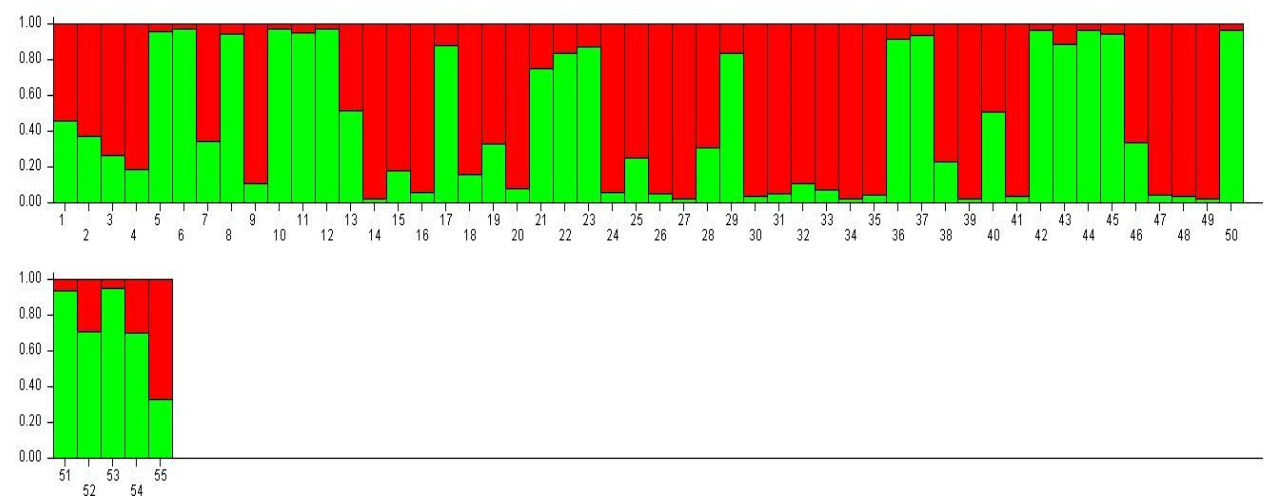

Fig 4: Population structure of pea accessions using SSR markers. 
and Handerson et al., (2014) in pea. The accessions of both phylogenic trees with low correlation showed the environmental effect on the accessions. Thus, despite its self-pollinating nature, the present study further reveals that pea germplasm is widely intermixed, resulting in greater diversity that breeders can study and utilize to develop new, improved pea varieties.

\section{CONCLUSION}

Accessions viz., VRP-82, VRP-320, VRP-194, VRP-375, EC97280 and EC-8724, showed great diversity as compared to the other accessions based on both morphological and molecular markers. These accessions may assist in developing and planning breeding strategies aimed to produce new varieties in the future. Further for better resolution of genetic diversity of the pea germplasm can be exploited by the use of higher number of polymorphic markers and more number of accessions.

\section{REFERENCES}

Bostein, D., White, R.L., Skolnick, M. and Davis, R.W. (1980). Construction of a genetic linkage map in man using restriction fragment length polymorphisms. American Journal of Human Genetics. 32: 314-331.

Choudhury, P.R., Tanveer, H. and Dixit, G.P. (2007). Identification and detection of genetic relatedness among important varieties of pea (Pisum sativum L.) grown in India. Genetica. 130: 183-187.

Cupic, T., Tucak, M., Popovic, S., Bolaric, S., Grljusic, S. and Kozumplik, V. (2009). Genetic diversity of pea (Pisum sativum $\mathrm{L}$.) accessions assessed by pedigree, morphological and molecular data. Journal of Food, Agriculture and Environment. 7: 343-348.

Doyle, J.J. and Doyle, J.L. (1987). A rapid DNA isolation procedure for small quantities of fresh leaf tissue. Phytochemical Bulletin. 19: 11-15.

Excoffier, L., Smouse, P.E. and Quattro, J.M. (1992). Analysis of molecular variance inferred from metric distances among DNA haplotypes: Application to human mitochondrial DNA restriction sites. Genetics. 131: 479-491.

Excoffier, L. (1993). Analysis of Molecular Variance (AMOVA) Version 1.55. In: Genetics and Biometry Laboratory, University of Geneva, Switzerland.

Handerson, C., Noren, S.K., Wricha, T., Meetei, N.T., Khanna, V.K., Pattanayak, A., Shiv, D., Choudhury, P.R. and Kumar, M. (2014). Assessment of genetic diversity in pea (Pisum sativum L.) using morphological and molecular markers. Indian Journal of Genetics. 74: 205-212.

Huang, Y., Liu, X., Cao, D., Chen, G., Li, S., Wang, G., Wang, J., Xu, S. (2021). Cross-species Amplification of Common Bean (Phaseolus vulgaris) EST-SSRs within Hyacinth Bean, Pea and Soybean. Legume Research. 44(3): 287291.

Jain, S., Kumar, A. and Mamidi, S. and McPhee, K. (2014). Genetic diversity and population structure among pea (Pisum sativum L.) cultivars as revealed by simple sequence repeat and novel genic markers. Molecular Biotechnology. 56: 925-938.
Kumar, M., Rakesh Sharma, V., Kumar, V., Sirohi, U., Chaudhary, V., Sharma, S., Saripalli, G., Naresh, R.K., Yadav, H.K., Sharma, S. (2019). Genetic diversity and population structure analysis of Indian garlic (Allium sativum L.) collection using SSR markers. Physiology Molecular Biology Plants. 25: 377-386. DOI: 10.1007/s12298-018-0628-y.

Loridon, K., McPhee, K., Morin, J., Dubreuil, P., Pilet-Nayel, M.L., Aubert, G., Rameau, C., Baranger, A., Coyne, C., LejeuneHenaut, I. and Burstin, J. (2005). Microsatellite marker polymorphism and mapping in pea (Pisum sativum L.). Theoretical and Applied Genetics. 111: 1022-1031.

Nagaraju, J., Reddy, K.D., Nagaraja, G.M. and Sethurama, B.N. (2001). Comparison of multilocus RFLPs and PCR-based marker systems for genetic analysis of the silkworm, Bombyx mori. Heredity. 86: 588-597.

National Horticulture Board. (2019). Indian Horticulture Database. http://www.nhb.gov.in.

Negisho, K., Teshome, A. and Keneni, G. (2017). Genetic diversity in Ethiopian field pea (Pisum sativum L.) germplasm collections as revealed by SSR markers. Ethiopian Journal of Agricultural Sciences. 27: 33-47.

Peakall, R. and Smouse, P. (2006). GENEALE × 6: Genetic Analysis in Excel. Population genetic software for teaching and research. Molecular Ecology Notes. 6: 288-295.

Prakash, N., Kumar, R., Choudhary, V.K. and Singh, C.M. (2016). Molecular assessment of genetic divergence in pea genotypes using microsatellite markers. Legume Research. 39: 183-188.

Prevost, A. and Wilkinson, M.J. (1999). A new system of comparing PCR primers applied to ISSR fingerprinting of potato cultivars. Theoretical and Applied Genetics. 98: 107-112.

Pritchard, J.K., Stephens, M. and Donnelly, P. (2000). Inference of population structure using multilocus genotype data. Genetics. 155: 945-959.

Rahman, M., Hasan, M., Chowdhury, R.N., Ivy, N.A. and Hossain, M.M. (2013). Genetic diversity in vegetable pea (Pisum sativum L.). Bangladesh Journal of Plant Breeding and Genetics. 26: 35-40.

Rana, J.C., Rana, M., Sharma, V., Nag, A., Chahota, R.K. and Sharma, T.R. (2017). Genetic diversity and structure of pea (Pisum sativum L.) germplasm based on morphological and SSR markers. Plant Molecular Biology. 35: 118-129.

Rohlf, F.J. (1998). NTSYSpc Numerical Taxonomy and Multivariate Analysis System Version 2.0 User Guide. Applied Biostatistics Inc Setauket New York.

Santalla, M., Amurrio, J.M. and De, Ron, A.M. (2001). Food and feed potential breeding value of green, dry and vegetable pea germplasm. Canadian Journal of Plant Sciences. 8: 601-610.

Singh, S., Sharma, V.R., Nannuru, V.K.R., Singh, B. and Kumar, M. (2021). Phenotypic Diversity of Pea Genotypes (Pisum sativum L.) Based on Multivariate Analysis. Legume Research. 44: 875-881.

Shrivastava, V., Lal, G.M., Chandra, K. and Singh, C.M. (2012). Estimation of genetic distance in field pea (Pisum sativum L.). Environment and Ecology. 30: 136-138.

Smykal, P., Hybl, M., Corander, J., Jarkovsky, J., Flavell, A.J. and Griga, M. (2008). Genetic diversity and population structure of pea (Pisum sativum L.) varieties derived from combined retrotransposon, microsatellite and morphological marker analysis. Theoretical Applied Genetics. 117: 413-424. 
Suman, S., Rani, B., Sharma, V.K., Kumar, H., Shahi, V.K. (2019). SSR marker based profiling and diversity analysis of mungbean [Vigna radiata (L.) Wilczek] genotypes. Legume Research. 42: 585-594

Tahir, A.R.N., Djshwar, D.L., Dlshad, A.O., Shadia, H.S.K., Dastan, A. and Lanja, H. (2018). Genetic diversity and structure analysis of pea grown in Iraq using microsatellite markers. Jordan Journal of Biological Sciences. 11: 201-207.
Uzma, A., Muhammad, J.A., Malik, A.R., Ayaz, A.A., Shahid, I.A. and Anisa, I. (2018). Genetic diversity of pea (Pisum sativum L.) landraces using morphological markers. International Journal of Biosciences. 13: 327-340.

Venables, W.N. and Ripley, B.D. (2002). Modern Applied Statistics with S, Springer-rlag.

Yeh, F.C. and Boyle, T.J.B. (1997). Population genetic analysis of co-dominant and dominant markers and quantitative traits. Belgium Journal of Botany. 129: 157. 